\title{
Spastic paraparesis-deafness syndrome
}

INSERM

\section{Source}

INSERM. (1999). Orphanet: an online rare disease and orphan drug data base. Spastic paraparesis-deafness syndrome. ORPHA:2815

Spastic paraparesis-deafness syndrome is a chronic neurodeg enerative disorder characterised by spastic paraparesis (beginning at about 10 years of age) and hearing deficits. 